\title{
Comparison of microbial activity in the cecum of ponies and donkeys
}

\author{
B Suhartanto, V Julliand, F Faurie, JL Tisserand \\ INRA-ENSSAA, laboratoire associé de Recherches zootechniques, 26, bd du Docteur-Petitjean, \\ 21000 Dijon, France
}

In this study, the ability of donkeys to utilize low quality diets with or without energy and nitrogen supplemention was compared to that in ponies.

Three ponies (mean live weight: $203 \mathrm{~kg}$ ) and 3 donkeys $(228 \mathrm{~kg})$ adult and cecal-fistulated were fed successively during 4 periods ( 2 wk adaptation and 1 wk of measurements), 4 diets based on wheat straw (WS, crude protein $3.4 \%$ $\mathrm{DM})$. The diets were offered ad libitum and were composed of $(\mathrm{g} / \mathrm{kg}): 770 \mathrm{WS}+150$ maize and 80 soybean meal (diet I); 785 WS +215 maize (diet II); diet II $+11 \mathrm{~g}$ urea (diet III, isonitrogenous to diet I) and 1000 WS (diet IV). The cecum juice was sampled before and 4, 6 and $8 \mathrm{~h}$ after the morning meal.

Wheat straw degradation measured in sacco for $24 \mathrm{~h}$ was not significantly different between donkeys and ponies; however, with low nitrogen diets (II and IV), it tended to be higher in donkeys. The higher concentration of volatile fatty acids (VFA) in the cecum juice of donkeys, due to more intensive microbial activity, was related to their straw intake $(43.0,41.0,41.9$ and $48.2 \mathrm{~g} / \mathrm{kg} \mathrm{W} \mathrm{W}^{0.75}$, ie $172 \%, 175 \%$, $157 \%$ and $140 \%$ the intake of the ponies for diets I - IV respectively). Consequently, the $\mathrm{pH}$ was lower in donkeys. The higher straw intake had no effect on digestibility but tended to decrease transit times in the digestive tract (Suhartanto et al, 1992). The supplementation of diets with energy and nitrogen increased the VFA concentration. The proportion of butyric acid was higher in donkeys than in ponies, while the proportion of acetic was lower. The cecum content, measured with polyethylene glycol 4000 , tended to be higher in donkeys than in ponies $(114,107$ and $104 \%$ for diets II, III and IV).

In conclusion, higher feed intake and persistency of microbial activity allows the donkey to utilize low quality forage better than the pony.

Suhartanto B, Julliand V, Faurie $F$, Tisserand $\mathrm{JL}$ (1992) $18^{e}$ Journée Rech Chevaline. CEREOPA, Paris

Table I. Degradation of wheat straw (dWS) in sacco, $\mathrm{pH}$ and concentration of volatile fatty acids (VFA; acetic, propionic and butyric acid) in the cecum of ponies (P) and donkeys (D): means of 4 samples $\pm S E$.

\begin{tabular}{|c|c|c|c|c|c|c|c|c|}
\hline \multirow[t]{2}{*}{ Parameters } & \multicolumn{2}{|c|}{ Diet 1} & \multicolumn{2}{|c|}{ Diet II } & \multicolumn{2}{|c|}{ Diet III } & \multicolumn{2}{|c|}{ Diet IV } \\
\hline & $P$ & $D$ & $P$ & $D$ & $P$ & $D$ & $P$ & $D$ \\
\hline dWS in sacco (\%) & $21.6 \pm 0.9$ & $21.4 \pm 2.8$ & $17.5 \pm 0.4$ & $19.0 \pm 0.3$ & $21.4 \pm 3.2$ & $19.7 \pm 2.6$ & $17.4 \pm 1.6$ & $17.7 \pm 1.0$ \\
\hline $\mathrm{pH}$ & $7.1 \pm 0.1$ & $6.8 \pm 0.0$ & $7.1 \pm .0 .0$ & $6.8 \pm 0.1$ & $7.0 \pm 0.0$ & $6.7 \pm 0.1$ & $7.1 \pm 0.0$ & $6.9 \pm 0.0$ \\
\hline VFA $(\mathrm{mmol} / \mathrm{I})$ & $40.1 \pm 5.1$ & $63.7 \pm 6.0$ & $39.4 \pm 1.1$ & $59.6 \pm 0.0$ & $43.6 \pm 1.5$ & $59.5 \pm 7.0$ & $30.9 \pm 0.3$ & $45.6 \pm 1.9$ \\
\hline Acetic acid (mol\%) & $65.3 \pm 0.5$ & $61.9 \pm 1.6$ & $67.8 \pm 2.9$ & $63.2 \pm 1.0$ & $67.8 \pm 2.9$ & $62.5 \pm 0.5$ & $69.8 \pm 2.1$ & $65.8 \pm 2.2$ \\
\hline Propionic acid (mol\%) & $28.1 \pm 0.4$ & $26.0 \pm 1.9$ & $25.9 \pm 2.7$ & $23.2 \pm 0.2$ & $25.2 \pm 2.5$ & $24.2 \pm 0.8$ & $23.4 \pm 1.6$ & $24.4 \pm 1.9$ \\
\hline Butyric acid (mol\%) & $4.9 \pm 0.2$ & $9.4 \pm 0.4$ & $5.2 \pm 0.2$ & $11.6 \pm 0.7$ & $6.3 \pm 0.0$ & $11.8 \pm 0.9$ & $5.8 \pm 0.5$ & $7.7 \pm 1.2$ \\
\hline
\end{tabular}

